\title{
Introdução ao Federalismo das Águas: interfaces entre gestão de bacias hidrográficas e saneamento básico
}

\author{
Introduction to the Water's Federalism: interfaces between manage- \\ ment of hidrográficas basins and basic sanitation
}

Benevenuto S. Santos 1

\begin{abstract}
Resumo
As cidades possuem, em quaisquer de suas escalas de crescimento, desafios próprios para garantir um quadro de políticas públicas permanentes e necessárias, que se proporcionarão uma boa qualidade de vida de seus cidadãos. As peculiaridades regionais e locais, com maior ou menor grau de intensidade, acarretam problemas intra-urbanos que afetam sua sustentabilidade, especialmente em questões como déficit de moradias adequadas, déficit de cobertura de saneamento ambiental, baixa qualidade de transporte público, além de toda marginalização social que surge com o crescimento demográfico. É importante tomar medidas normativas e reguladoras que evitem a insustentabilidade nos padrões de degradação dos recursos naturais, imprescindíveis para a economia e para o desenvolvimento urbano. Contudo, em termos ambientais e urbanos, algumas metas só poderão ser atingidas em longo prazo, desde que os entes federativos atuem em parceria e entre estes e a sociedade, introduzindo políticas urbanas capazes de oferecer resultados e, gradualmente, apropriando-se das próprias experiências.
\end{abstract}

Palavras-Chaves: Federalismo; Bacias Hidrográficas; Saneamento

\begin{abstract}
The cities has, in any of its scales of growth, proper challenges to guarantee a picture of permanent and necessary public politics, that will provide a good quality of life of its citizens. The regional and local peculiarities, with greater or minor intensity degree, cause intra-urban problems that affect its sustainability, questions as deficit of housings especially adjusted, deficit of covering of enviroment sanitation, low quality of public transport, beyond all social marginalization that appears with the demographic growth. It is important to take measured normative and regulating that prevents the insustainability in the standards of degradation of the natural resources, essential for the economy and the urban development. However, in enviroment and urban terms, some goals alone could be reached in the long run, since that the federative beings act in partnership and between these and the society, introducing urban politics capable to offer resulted e, gradually, assuming itself of the proper experiences.
\end{abstract}

Key-words: Federalism; Basins; Sanitation

${ }^{1}$ Mestre - Ciências Humanas e Sociais Aplicadas - UniFOA

benevenutofss@uol.com.br 


\section{Aspectos gerais do problema}

Os problemas relacionados com a gestão urbana, especificamente proteção dos mananciais hídricos e serviços públicos de saneamento, devem ser inseridos no conceito de desenvolvimento urbano, promovendo uma gestão eficaz do território. Não há como estabelecer um quadro de medidas governamentais, legislativas e administrativas, sem o estudo de soluções interligadas.

Relatamos, a seguir, as ações setoriais que estão envolvidas no contexto do serviço de saneamento básico. A estratégia para prestação de serviço de saneamento é delineada por modelos que trabalham três segmentos correlatos e diferenciados de ações governamentais:

1)Aspectos espaciais de planejamento e gestão, envolvendo a necessidade de planejamento de ações em várias escalas e adequados às características regionais de rede urbana, controle ambiental e fortalecimento de bacias hidrográficas ${ }^{1}$;

2)Fortalecimento da gestão democrática, consolidando instrumentos de informações e monitoramento públicos;

3)Regulamentação da gestão de saneamento ambiental, por meios de atuação compartilhada, por estados e municípios, linhas de financiamento desburocratizadas e simplificadas, qualidade na prestação de serviços públicos, redução de custos e desperdícios.

Estas estratégias terão, no contexto do saneamento, que enfrentar problemas tais como: combater o desperdício; reduzir perdas nos sistemas de saneamento; reduzir a geração de resíduos, de dejetos, de poluentes nas áreas urbanas, além de buscar soluções no cenário definido, que registram a exclusão social e espacial como circunstâncias preponderantes no urbano brasileiro.

Dentre as providências imediatas a serem tomadas, no sistema jurídico no qual vivemos, no Brasil, em decorrência das recomendações da Agenda 21, está o fortalecimento da descentralização das po- líticas públicas ambientais e urbanas, privilegiando a economicidade dos investimentos, o acesso de todos à água tratada e à proteção contra riscos ao ambiente equilibrado, a aplicação do princípio da subsidiariedade, proporcionando delegação de tarefas e recursos proporcionais à gestão democrática.

Os próximos tópicos abordarão algumas políticas públicas em matérias comuns e exercidas de forma descentralizada, com a participação dos entes federativos locais, que repercutem diretamente, em matéria de saneamento ambiental, evidenciando, assim, o aspecto multidisciplinar do tema.

Expandir e melhorar os serviços públicos de água e saneamento, e zerar a restrição de acesso a esses serviços essenciais, deveria ser um dos principais objetivos do Federalismo brasileiro, pois estes constituem obstáculos ao desenvolvimento e importantes fatores da desigualdade social e econômica que caracteriza nosso país, no contexto internacional. Entre outros temas, as enfermidades passíveis de prevenção relacionadas com a água, continuam sendo uma das causas principais de morbi-mortalidade e, ainda que algumas doenças tenham sido erradicadas, o fator hídrico sempre será um veículo para que elas retornem, nos dias atuais. A ausência de políticas públicas integradas e eficientes, desde a década de 90 , tem contribuído para exacerbar os problemas existentes, especialmente os conflitos sociais e políticos pela água, a desigualdade no acesso aos serviços e a falta de controle democrático sobre a gestão.

Por outro lado, consolida-se uma tomada de consciência, crescente, de que não há crescimento econômico sem uma política de infra-estrutura urbana, viável e generalizada, mediante os processos de cooperação para ações executivas e elaboração de políticas públicas mediante acordamentos previamente definidos. Em relação à água, os graves problemas acumulados, durante décadas, de políticas baseadas na intervenção drástica sobre os ecossistemas aquáticos, freqüentemente implementadas mediante processos autoritários, sem debate público, nem controle democrático, têm conduzido a uma deterioração dos ecossistemas, mediante processos de contaminação e redução das fontes de água, rios, lagos, aqüíferos, charcos e outros corpos hídricos.

${ }^{1}$ Conjunto constituído por um rio, seus afluentes e mesmo as águas subterrâneas, formando o que se chama de sistema hidrográfico. COLLIARD, Claude-Albert. Régime dès fleuves internationaux. In: Recueil dès Cours. 1968, v. 3, t. 125, p. 398. Apud GRANZIERA, Maria Luiza Machado. Direito das águas: disciplina jurídica das águas doces. São Paulo: Atlas, 2001, p. 37. 
Simultaneamente, com freqüência, estas intervenções têm tido, também, um efeito negativo sobre amplos setores da população, como são as alterações no ciclo natural dos rios que levam a inundações mais freqüentes e destrutivas. Este lado negativo dos processos de desenvolvimento segue sendo pouco debatido, apesar dos problemas gerados continuarem afetando, gravemente, a qualidade de vida e o bemestar de milhões de pessoas.

Existe um reconhecimento crescente de que, para enfrentar com êxito os desafios que se apresentam em relação à gestão da água e dos serviços públicos de água e saneamento, há necessidade de alteração substancial nas políticas, nas instituições e na forma com que os seres humanos se relacionam com a água, em nossa cultura.

\section{As Políticas Públicas de Saneamento}

Entre as atribuições dos órgãos públicos, em matéria de ações de saneamento básico, temos o art. 23, das competências comuns, inciso IX, promovendo programas de construção de moradias e melhoria das condições habitacionais e de saneamento básico.

As ações de saneamento devem estar voltadas para proteção e prevenção de vários setores que envolvem a atuação do Estado, sendo a saúde pública, um desses. Os impactos sociais e econômicos destas doenças e da subnutrição colaboram com um quadro de pauperização, levando o país a uma situação de calamidade e violência urbana.

$\mathrm{O}$ atendimento a doenças decorrentes de más condições sanitárias absorve, certamente, parte dos recursos públicos em saúde, que poderiam ser mais bem utilizados em outras áreas ou programas específicos. A existência de ações urbanas, em matéria de saneamento, é necessária e óbvia para rearticular toda política de gastos governamentais.

A Pesquisa Nacional de Saneamento Básico 2000 revela que $97,9 \%$ dos municípios brasileiros têm serviço de abastecimento de água, 78,6\% têm serviço de drenagem urbana e 99,4\% têm coleta de lixo. O esgotamento sanitário ainda é o serviço que apresenta a menor taxa, mas já é oferecido em mais da metade $(52,2 \%)$ dos municípios brasileiros ${ }^{2}$.

Em 2000, o serviço de abastecimento, prestado por alguma empresa pública ou privada, alcançou uma proporção de 97,9\% dos municípios do País, enquanto em 1989 abrangia 95,9\%. A pesquisa revelou que 116 municípios brasileiros, ou 2\% do total, não têm abastecimento de água por rede geral; a maior parte deles situado nas regiões Norte e Nordeste.

A abrangência do abastecimento de água também varia de acordo com o tamanho populacional dos municípios: quanto mais populosos forem, maiores as proporções de domicílios abastecidos. Os menores municípios apresentam maior deficiência nos serviços e apenas $46 \%$ dos domicílios situados em municípios com até 20000 habitantes contam com abastecimento de água por rede geral.

Em 2000 foram distribuídos, diariamente, no conjunto do país, 0,26 m3 (ou 260 litros) de água per capita, média que variou bastante entre as regiões. $\mathrm{Na}$ região Sudeste, o volume distribuído alcançou 0,36 m3 per capita, enquanto no Nordeste ele não chegou à metade, apresentando uma média de $0,17 \mathrm{~m} 3$ per capi$\operatorname{ta}^{34}$.

O esgotamento sanitário é o serviço de saneamento básico com menos cobertura nos municípios brasileiros, embora tenha crescido $10,6 \%$. Se, em 1989, dos 4.425 municípios existentes no Brasil, 47,3\% tinham algum tipo de serviço de esgotamento sanitário, em 2000, dos 5.507 municípios, 52,2\% tinham esgotamento sanitário, o que representa um crescimento de 10\% no período de 1989-2000.

\footnotetext{
${ }^{2}$ A pesquisa, realizada em convênio com a Secretaria Especial de Desenvolvimento Urbano da Presidência da República (SEDU/PR), com a Fundação Nacional de Saúde (FUNASA) e com a Caixa Econômica Federal, apresenta um perfil da oferta de serviços de saneamento básico em todos os municípios brasileiros, com resultados até o nível de distritos, permitindo, assim, identificar as demandas regionais de investimentos públicos nos serviços que estão mais diretamente relacionados à saúde e à qualidade de vida da população.

${ }^{3}$ Entre 1989 e 2000, o volume total de água distribuída, por dia, no Brasil cresceu 57,9\%. Em 1989, dos 27,8 milhões de m3 de água distribuídos diariamente, $3,9 \%$ não eram tratados. Em 2000, a proporção de água não tratada quase dobrou, passando a representar 7,2\% do volume total ( 43,9 milhões de m3 por dia). Vários distritos, porém, são abastecidos com água subterrânea, como nos estados do Pará ( 89\%) e Rio Grande do Sul (75\%), que, embora não tratada, pode ter boa qualidade.

${ }^{4}$ A proporção da água distribuída com tratamento também varia de acordo com o tamanho da população dos municípios. Naqueles com mais de 100000 habitantes, a água distribuída é quase totalmente tratada. Já nos municípios com menos de 20000 habitantes, 32,1\% do volume distribuído não recebe qualquer tipo de tratamento.
} 
No Brasil, 33,5\% dos domicílios são atendidos por rede geral de esgoto. Nos municípios, a desigualdade dos serviços prestados se repete: quanto maior a população do município, maior a proporção de domicílios com serviço de esgoto. Os municípios com mais de 300.000 habitantes têm quase três vezes mais domicílios ligados à rede geral de esgoto do que os domicílios em municípios com população até 20.000 habitantes $^{5}$.

Em relação ao esgotamento sanitário, 47,8\% dos municípios brasileiros não têm coleta de esgoto. O Norte é a região com a maior proporção de municípios sem coleta (92,9\%), seguido do Centro-Oeste $(82,1 \%)$, do Sul $(61,1 \%)$, do Nordeste $(57,1 \%)$ e do Sudeste $(7,1 \%)$. Nesses casos, os principais receptores do esgoto in natura não coletado são os rios e mares, comprometendo a qualidade da água utilizada para abastecimento, irrigação e recreação ${ }^{6}$.

Dos 5.507 municípios brasileiros, 4.026, ou seja $73,1 \%$, têm população até 20.000 habitantes. Nestes municípios, $68,5 \%$ dos resíduos gerados são vazados em lixões e em alagados. Se tomarmos, entretanto, como referência, a quantidade de lixo por eles gerado, em relação ao total da produção brasileira, a situação é menos grave pois, em conjunto, coletam somente $12,8 \%$ do total brasileiro (20.658 $\mathrm{t} / \mathrm{dia})$. Isto é menos do que o gerado pelas 13 maiores cidades brasileiras, com população acima de um milhão de habitantes. Só estas coletam $31,9 \%$ (51.635 t/dia) de todo o lixo urbano brasileiro e têm seus locais de disposição final em melhor situação: apenas 1,8 \% (832 t/dia) é destinado a lixões. $\mathrm{O}$ restante sendo depositado em aterros controlados ou sanitários. A maioria $(57,7 \%)$ dos municípios com instrumentos reguladores usa a Lei de uso e ocupação do solo como regulamentação. ${ }^{7}$

Do quadro ilustrado, pode-se chegar à constatação de que há uma omissão administrativa no ser- viço de coleta e tratamento de esgoto sanitário, exercido por Estados e Municípios, serviço devidamente retribuído pelos usuários ou contribuintes.

\section{Saneamento e Políticas Públicas Regionais}

A estrutura urbana formada no Brasil levou à concentração de sistemas polarizados e a eixos de ocupação urbana, da qual a metrópole é a principal característica. Isso acentua a concentração da população urbana nas áreas metropolitanas e em aglomerações urbanas, reforçando os desequilíbrios de redes de cidades, recrudescendo problemas sociais, urbanos e ambientais nos grandes centros, sem esquecer que até os investimentos necessários causam efeitos danosos à cidade sustentável. Necessária se faz uma reformulação na intervenção no território e nas áreas urbanas, conferindo importância ao planejamento do desenvolvimento regional, que podem se constituir em meio reestruturador das políticas voltadas para a transformação das cidades brasileiras. As cidades devem ser consideradas como parte integrantes das suas respectivas regiões e microrregiões, ${ }^{8}$ em função de condicionantes territoriais de sustentabilidade.

O perfil da demanda por serviços de saneamento ambiental guarda relação histórica com exclusão social e a segregação espacial e tem seus contornos definidos por fatores como:

a) a distribuição desigual do acesso aos serviços segundo faixas de renda da população;

b) a regionalização das carências, que configura as diferenças e as desigualdades entre as áreas centrais, intermediárias e periféricas das cidades brasileiras e o nível de precariedade dos setores sócio-

\footnotetext{
${ }^{5}$ No Sudeste, as diferenças não são tão marcantes: $58,7 \%$ dos domicílios nos municípios com mais de 300.000 habitantes e $42,1 \%$ dos domicílios nos municípios com até 20.000 habitantes têm rede geral de esgoto. Já no Nordeste, os municípios com mais de 300.000 habitantes têm 3,4 vezes mais domicílios com rede geral do que os municípios com 20.000 habitantes. A maior diferença de domicílios servidos em municípios de grande e pequeno porte encontra-se na região Centro-Oeste: os municípios com população acima de 300.000 têm 20 vezes mais domicílios com rede geral de esgoto do que os municípios com 20.000 habitantes (56,7\% e 2,6\%, respectivamente).

${ }^{6}$ No Brasil, dos 52,2\% dos municípios que têm esgotamento sanitário, 32,0\% têm serviço de coleta e 20,2\% coletam e tratam o esgoto. Em volume, no país, diariamente, 14, 5 milhões m3 de esgoto são coletados, sendo que 5,1 milhões m3 são tratados. O Sudeste é a região que tem a maior proporção de municípios com esgoto coletado e tratado (33,1\%), seguido do Sul $(21,7 \%)$, Nordeste $(13,3 \%)$, Centro-Oeste $(12,3 \%)$ e Norte $(3,6 \%)$.

${ }^{7}$ Disponível em: http://www.ibge.gov.br/home/presidencia/noticias/27032002pnsb.shtm. Acesso em 15/ jan / 2006

${ }^{8}$ BEZERRA, Maria do Carmo Lima; FERNANDES, Marlene Allan (coordenação geral). Cidades sustentáveis: subsídios à elaboração de Agenda 21 brasileira. Brasília: Ministério do Meio Ambiente; Instituto do Meio Ambiente e dos Recursos Naturais Renováveis, 2000 , p 43.
} 
econômicos mais pauperizados da população;

c) a espacialidade, característica do processo de urbanização ocorridos no país, que implica maiores dificuldades físicas, financeiras e legais para a implantação de redes nas periferias brasileiras;

d) a associação íntima entre a mortalidade infantil e índices de atendimento nos serviços de saneamento, que indica uma explicação estrutural de profunda crise da saúde pública no Brasil;

e) a feminilização da pobreza, que confirma a concentração dos desassistidos em famílias de baixa renda e que tem uma mulher no papel de chefe;

f) a perversa degradação ambiental e pobreza urbana que revela a necessidade de integração setorial e de articulação institucional de políticas públicas. ${ }^{9}$

Percebemos que a preocupação com os aspectos regionais está entre as metas de um sistema integrado de prestação de serviços de saneamento, ou mesmo da implementação de políticas públicas integradas. Englobando o aspecto anterior de saúde pública e passando por questões sobre as formações territoriais, vemos que ambos são fatores que carecem de ações eficazes de saneamento, mais urgentes à medida que absorvem do poder público quantia orçamentária de maior monta. É um ciclo vicioso e autofágico. Se não houver investimentos em habitação e respectivas complementaridades, como saneamento ambiental, gastar-se-á mais em áreas sub-habitadas, cuja melhoria, a despeito de qualquer atividade criativa do poder público, será mais dispendiosa e irremediável. Se não se investe em saneamento, gastar-se-á mais em saúde e em políticas regionais ambientais de combate à degradação decorrente da presença humana. Se não houver investimento em saneamento nestas áreas, que sempre necessitam de recursos públicos, mais dificultosa será a tarefa de encontrar soluções para erradicar tais desigualdades. Regiões de alta concentração demográfica, espalhadas pelo Brasil, reúnem problemas que se associam à gestão da água e seus serviços derivados.

Eventuais riscos, derivados de eventos extremos, como as secas, as inundações recorrentes ou os acidentes nas infra-estruturas hidráulicas, exigem medidas preventivas, em situação de constante alerta, a fim de combater possíveis calamidades públicas.

\section{Saneamento Básico no Contexto Urbano - A Questão da Ocupação Urbana}

A gestão da água e seus serviços derivados, em áreas urbanas, apresentam características e desafios específicos.

O déficit de saneamento ocorre principalmente em assentamentos humanos irregulares, como loteamentos clandestinos e favelas, onde, também, não há provisão de outros serviços públicos, como recolhimento de lixo, segurança pública, educação, saúde, etc. Tais assentamentos têm origem no acelerado processo de urbanização desigual por que passaram, e passam, as cidades brasileiras. ${ }^{10}$

Esses assentamentos, que surgem sem qualquer infra-estrutura, exigindo, do poder público, investimentos pesados, quando realizados posteriormente à ocupação, estariam sob a responsabilidade do loteador, caso a formalidade fosse obedecida. Muitos se situam a grande distância da área urbanizada, o que aumenta ainda mais os custos e as deseconomias próprias das áreas urbanas desarticuladas, quando da urbanização. A provisão de abastecimento de água e coleta de esgotos apresenta enormes dificuldades, pelas peculiaridades dos assentamentos, uma vez que não há projeto urbanístico definido, nem segurança jurídica sobre a situação fundiária. Mesmo nos casos em que a regularização e a urbanização acabam por ser realizadas chamam a atenção, na política pública definida para a regularização fundiária, as dificuldades jurídicas e cartoriais, que empurram os processos para a complexidade burocrática.

\footnotetext{
${ }^{9}$ BEZERRA, Maria do Carmo Lima; FERNANDES, Marlene Allan (coordenação geral). Cidades sustentáveis: subsídios à elaboração de Agenda 21 brasileira. Brasília: Ministério do Meio Ambiente; Instituto do Meio Ambiente e dos Recursos Naturais Renováveis, 2000, p. 47-48.

${ }^{10}$ A ocupação desordenada e irregular impossibilita a disponibilização do saneamento de forma legalizada, acarretando na busca de solução clandestina, constituídos pelos próprios invasores, para sanar as necessidades primárias dessa população marginalizada e que constitui fonte latente de contaminação da rede pública regular. CARDIA, Regina Helena Piccolo. Ocupação territorial e meio ambiente. In: Revista de Direitos Difusos. São Paulo, v.22, 3045-3054, Nov/Dez 2003.
} 


\section{Saneamentos e Gestão de Recursos Hídricos}

A melhoria dos serviços de saneamento envolve analisar o problema adicionado a outros dois enfoques: recursos hídricos e meio ambiente.

O gerenciamento eficiente dos recursos hídricos, tanto no Brasil como em outros países em estado de desenvolvimento, depende de investimentos volumosos em programas de infra-estrutura básica, relacionados aos diferentes usos de águas.

A gestão de recursos hídricos constitui um primeiro movimento para formulação de políticas que atendam à qualidade de vida. As entidades e instituições públicas que atuam nas questões afins aos recursos hídricos vêm exercendo suas atribuições desarticuladamente, de maneira independente cada uma, sem qualquer vínculo com as políticas de abastecimento de água e gestão de efluentes urbanos (além dos industriais).

Um dos pilares de qualquer política de preservação das fontes hídricas está no controle da poluição das águas, desenvolvendo uma gestão estratégica da água no âmbito das bacias hidrográficas ou de unidades geográficas semelhantes. ${ }^{11}$

As bacias hidrográficas são o centro das ações articuladas entre Estado, sociedade e usuários dos recursos hídricos disponíveis. A Lei 9.433/97, que instituiu o Sistema Nacional de Gerenciamento de Recursos Hídricos, dando cumprimento ao art. 21, XIX, da Constituição Federal, estatui um modelo padrão de interação entre os diversos atores envolvidos na questão ambiental, privilegiando, nitidamente, a utilização racional do bem hídrico, a prevalência do princípio da dignidade humana e a participação social no debate das questões que norteiam a preservação da água. Esta Lei poderia ter sido estruturada em um número maior de dispositivos, introduzindo no cerne da questão a total articulação entre ações de saneamento e captação de águas. Mas, ainda assim, é um enorme avanço institucional e normativo para o Brasil.

Dentre os mecanismos abordados pela lei geral de águas temos:

- reconhecimento da água como bem econômico passível de escassez e conseqüente cobrança pelo seu uso;

- instituição do plano de bacias, como referencia administrativa para ações de preservação do bem;

- Participação da sociedade civil no plano de bacias;

- Fortalecimento do papel fiscalizador e normativo do Poder Público;

- A outorga como instrumento de controle sobre o uso da fonte hídrica, compatibilizando desenvolvimento econômico e sobrevivência do meio ambiente.

Segundo PAULO DE BESSA ANTUNES, através da outorga o Estado passa a ter controle sobre a captação e o lançamento ed efluentes nos corpos de água. ${ }^{12}$

$\mathrm{O}$ art. 12 da Lei 9.433/97, descreveu quais os direitos que se encontram submetidos ao regime de outorga:

a)derivação ou captação de parcela de água existente em corpo de água para consumo final, inclusive abastecimento público, ou insumo de processo produtivo;

b)extração de água de aquífero subterraneo para consumo final ou insumo em processo produtivo; c)lançamento em corpo de água de esgoto e demais resíduos líquidos ou gasoso, tratados ou não, com o fim de diluição, transporte ou disposição final; d)aproveitamento de potencial hidrelétrico; e)outros usos que alteram o regime, a quantidade ou a qualidade da água existente em um corpo de água.

Desse modo, aos menos na primeira fase da prestação de serviços de saneamento e na última, captação e lançamento, que incidem diretamente na qualidade do corpo de água, o órgão regulador (fiscalizador e normativo) do uso da água poderá funcionar com regulador de uma das etapas da gestão ambiental urbana.

A maior crítica que pode ser feito analisando a lei das águas está no abandono de uma relação institucional e vinculada entre os rios estaduais e os rios federais que lhe dão vazão, como ocorre com os rios Piraí e Guandu, no sul do Estado do Rio de Janeiro, este último completamente dependente do primeiro.

\footnotetext{
${ }^{11}$ MARGULIS; Sérgio et al. Brasil: a gestão da qualidade da água. Inserção de temas ambientais na agenda do setor hídrico. Nova York: Banco Mundial, 2002 
O fator de interação entre saneamento e preservação dos rios e fontes hídricas concentra-se na política sustentável de captação, como já dito, no contexto da gestão das bacias hidrográficas. Desse problema de captação, ou da má captação, entre as várias razões para a degradação do bem hídrico, está a má ocupação do solo urbano.

É notável que as doutrinas nacionais relacionadas ao direito ambiental não façam menção a políticas de gestão urbana na prevenção do bem esgotável constituído pela água, não difundindo a defesa da sua gestão referente ao saneamento básico. Na falta de abastecimento de água potável, os domicílios freqüentemente usam água com algum grau de contaminação e na falta de coleta adequada de esgotos, o material fecal continua no domicílio ou na vizinhança, o que leva à transmissão de doenças. ${ }^{13}$

Um outro aspecto a destacar, no que se refere à organização do setor de saneamento, é sua insuficiente articulação com programas e atividades de outras áreas, especialmente aquelas relacionadas com o meio ambiente e a gestão dos recursos hídricos. ${ }^{14}$

A gestão integrada de bacias hidrográficas inclui mecanismos institucionais entre os níveis de governo (local, regional, nacional), planejando ações com a participação social, com o objetivo de promover a racionalização da água para os múltiplos aproveitamentos, tais como o uso humano essencial, uso público, usos industriais e agrícolas, funções ambientais, etc. A União e os Estados-membros, na qualidade de titulares do domínio sobre as fontes hídricas, assumem funções em caráter geral e os Municípios atuando nas questões de interesse local, provocando e impondo medidas que incidentalmente promoverão a proteção dos rios, tais como proteção de mananciais coibindo o lançamento de dejetos e entulhos e participando dos serviços de dragagem em faixas de menor extensão entre as margens.
O debate sobre a racionalidade econômica e os impactos ambientais e sociais de obras ambientais e a necessidade de revisar o conceito de "interesse geral", tradicionalmente associado à realização de grandes obras em novas razões de valores e princípios, devem ser priorizados quando na possibilidade de novos investimentos públicos ou privados.

\subsection{Gestão de águas subterrâneas}

Os aquíferos constituem fonte de água doce sujeita à utilização dentro de um contexto que englobe as fontes superficiais, sendo uma das modalidades de captação que depende da autorização do Estado-membro em que estiver localizada.

São bens estaduais, conforme disposto no art. 26 da Constituição da República. A utilização de aqüíferos $^{15}$ deve apresentar uma relação com a gestão das bacias, como fonte alternativa à possível escassez, indicando parâmetros de sustentabilidade para cada caso. O manejo integral de águas subterrâneas e superficiais deve obedecer a aspectos traçados pela sociedade envolvida.

Os mananciais de água subterrânea estão inseridos na gestão integrada de águas no Brasil, sob pena de extração desordenada, provocando impactos das descargas dos rios.

\subsection{A prevenção ambiental em questões de sanea- mento}

O detalhamento do estudo do setor de saneamento no contexto da gestão hídrica merece ser direcionado a dois pontos-chave: o usuário dos serviços de saneamento e a garantia de um controle sobre a gestão da qualidade do ambiente.

\footnotetext{
${ }^{13}$ FREITAS, Marcos Aurélio Vasconcelos de; SILVA, Heloisa Kehrig de Souza e; ALVES, Rodrigo Flecha Ferreira. O estados das águas no Brasil. Brasília: ANEEL/MMA/MME, 1999, p. 85.Está claro que tal situação representa um ônus para a qualidade de vida das populações não assistidas, já que é comprovada a estreita dependência entre saneamento e saúde pública. Segundo o Ministério da Saúde, $65 \%$ das internações hospitalares resultam da inadequação dos serviços e ações de saneamento, sendo a diarréia responsável, anualmente, por 50 mil mortes de crianças, a maioria com menos de um ano de vida. Por falta de saneamento o cólera encontra nas periferias urbanas e nos bolsões de pobreza as condições ideais para sua disseminação.

${ }^{14}$ Idem, p. 85

${ }^{15}$ O Estado de São Paulo é o maior usuário de águas subterrâneas do Brasil, tendo cerca de $65 \%$ de seus núcleos urbanos e, aproximadamente $90 \%$ das indústrias abastecidos parcial ou totalmente por poços. Não por acaso, é o Estado que concentra as maiores preocupações quanto à poluição e à contaminação. GRAF, Ana Cláudia Bento. A Tutela dos Estados sobre as águas. In: FREITAS, Vladimir Passos. Águas: aspectos jurídicos e ambientais. Curitiba: Juruá, 2000, p. 62-63. Nota-se que a preocupação referente a esta fonte não está na gestão de bacias, mas nos recursos hídricos em geral, e na sua utilização para suprir ausência de águas urbanas.
} 
No direito positivo, a prevenção é a ação destinada à preocupação com a higiene urbana, com o intuito de evitar dano detectado anteriormente. Trata da durabilidade da vida, da continuidade do meio ambiente para gerações humanas. ${ }^{16}$

O princípio da prevenção não objetiva a tolerância para com os poluidores, mas evitar o dano ao meio ambiente, ${ }^{17} \mathrm{em}$ que o mero pagamento pelo lançamento de dejetos ou produtos com alto potencial poluente não é o suficiente como medida protetiva, permitindo condutas inconseqüentes pelo simples fato de pagar multas decorrentes de infrações administrativas.

No contexto de gestão integrada, de evitar danos maiores ao ambiente, a atuação preventiva poderia ser efetiva em relação ao conjunto das empresas ou entidades, ou mesmo pessoas, que têm potencial poluente. A prevenção envolve exercício do poder de polícia, inclusive da autoridade de gestão de bacias.

A Lei 9.433/97 colocou à disposição do gestor hídrico dois instrumentos importantes para tratar o controle de qualidade na captação e no lançamento em fontes hídricas: a outorga e a cobrança pelo uso.

A melhor forma de adotar o princípio da prevenção, num contexto de distribuição de águas a uma densidade populacional acima de qualquer média é o instrumento da suspensão da outorga. É uma medida que concerne ao gestor da bacia.

Poder-se-ia exercitar esta polícia preventiva nas etapas do ciclo de saneamento, além da própria captação e do lançamento, no mesmo enfoque da relação outorgante / captador-lançador. Esta é uma questão a ser debatida.

\section{Saneamento Ambiental e Saneamento Básico}

Por definição, o saneamento ambiental ${ }^{18}$ abrange diversos elementos, dentre os quais o abastecimento de água, coleta e tratamento de esgotos, a drenagem, coleta e destinação de resíduos sólidos e controle de vetores transmissores de doenças ${ }^{19}$.

Para Arlindo Philippi Jr., o saneamento do meio pode ser definido como "o controle de todos os fatores do meio físico do homem que exercem ou podem exercer efeito deletério sobre seu bem-estar físico, mental e social". Desse modo, fazem parte desse saneamento: sistema de abastecimento de águas; sistema de coleta e tratamento de águas residuárias; sistema de limpeza pública; sistema de drenagem pluvial; controle de artrópodes e roedores de importância para a saúde pública (moscas, mosquitos, baratas, ratos e outros); controle de poluição das águas, do ar e do solo; saneamento de alimentos; saneamento dos meios de transporte; saneamento de locais de reunião e recreação; saneamento de locais de trabalho; saneamento de escolas; saneamento de hospitais; saneamento de habitações; saneamento no planejamento territorial; saneamento em situações de emergência e outros.

Em sentido estrito, as ações de saneamento básico envolvem os serviços de abastecimento de água e esgotamento sanitário, sendo composto, o sistema de saneamento básico, pelos sub-sistemas de abastecimento d'água, de águas residuárias, de limpeza pública e de drenagem urbana ${ }^{20}$ :

a) Um sistema de abastecimento de água se compõe do conjunto de atividades, obras, equipamentos e serviços que tem por função a proteção do manancial de águas, a captação, adução, tratamento, reservação, distribuição e consumo da água pela população,

\footnotetext{
${ }^{16}$ MACHADO, Paulo Affonso Leme. Direito ambiental brasileiro. 12. ed. Malheiros: São Paulo, 2004, p. 55.

${ }^{17}$ MILARÉ. Edis. Direito do ambiente. 3. ed. São Paulo: Revista dos Tribunais, 2004, p. 143.

${ }^{18}$ A Organização Mundial de Saúde entende por saneamento do ambiente o controle de todos os fatores que, no meio físico da vida humana, exercem ou podem exercer algum efeito nocivo no desenvolvimento do homem, a sua saúde e sua sobrevivência. É conceito largo que engloba não apenas o abastecimento d'água e o destino dos dejetos, mas ainda problemas relativos ao lixo, à habitação, à higiene alimentar, industrial e escolar, as formas de poluição e ao controle de vetores de doenças, pelo menos. FREIRE, Gilberto (coordenador); MOTA, Roberto. Trópico \& saneamento, solos, vias férreas, estudos de pós-graduação, iluminação, favela, comunicação e móvel. Conferencista Sebastião Barreto Campello. Saneamento e trópico. Recife: Editora Universitária, 1978, p. 61.

${ }^{19}$ PHILIPPI Jr., Arlindo; MALHEIROS, Tadeu Fabrício. Saneamento ambiental e saúde pública. In: PHILIPI Jr., Arlindo; ALVES, Alaôr Caffé. Curso interdisciplinar de direito ambiental. São Paulo: Manole, 2005, p. 62.

${ }^{20}$ PHILIPPI Jr., Arlindo; MALHEIROS, Tadeu Fabrício. Saneamento ambiental e saúde pública. In: PHILIPI Jr., Arlindo; ALVES, Alaôr Caffé. Curso interdisciplinar de direito ambiental. São Paulo: Manole, 2005, p. 62-63.
} 
em padrões de qualidade e quantidade que garantam proteção à saúde pública e ao meio ambiente.

b) Um sistema de águas residuárias é composto pelo conjunto de obras, equipamentos e serviços que tem, por função, a coleta, o transporte, o tratamento e a disposição final das águas residuárias, de modo a proteger a saúde pública, atendendo aos padrões legais existentes e protegendo o meio ambiente.

c) Um sistema de limpeza pública inclui atividades, serviços, equipamentos e obras que têm, por função, o acondicionamento, a coleta, o transporte, o tratamento e a disposição final dos resíduos sólidos produzidos por determinada comunidade. Deve incluir, também, e principalmente, ações que promovam a redução da geração de resíduos por meio de ações de educação ambiental, pesquisa em tecnologias que atendam aos princípios de desenvolvimento sustentável, bem como priorização em investimentos em reuso e reciclagem de produtos.

d) Um sistema de drenagem pluvial abrange as bacias urbanas, as calhas das ruas, as galerias, as escadarias, as rampas, até a chegada das águas aos córregos, rios e riachos, bem como os serviços e equipamentos necessários ao bom funcionamento do sistema e sua integração com os demais sistemas do saneamento do meio.

Este setor tem interfaces com as diversas políticas públicas de impacto social, tais como meio ambiente, saúde e política de ocupação urbana. ${ }^{21}$ Difícil é entender a questão de saneamento ambiental sem um contexto do ambiente, e imaginar ações de saneamento sem uma política mais ampla de infra-estrutura urbana.
Os dejetos urbanos lançados por domicílios e indústrias é a principal forma de poluição dos recursos hídricos, comprometendo os demais usos, inclusive o próprio abastecimento de água dos municípios à jusante.

\section{Características do Serviço de Saneamento Básico}

As características intrínsecas dos serviços de saneamento básico relacionam-se ao interesse direto da coletividade, em função da sua essencialidade, juntamente com a questão do monopólio natural dos dutos e tornam este tipo de prestação em um serviço público, sujeito a um regime jurídico de concessão ou permissão $^{22}$.

A duplicação dos sistemas de dutos, verdadeiros sistemas de transporte da água potável, necessários à prestação de tais serviços, seria mais custosa ou mesmo inviável em qualquer situação. Portanto, estes serviços são prestados normalmente por um único agente por região geográfica.

Dada a estrutura da prestação dos serviços públicos de saneamento básico, a qual, frise-se, depende de rede de difícil ou, até mesmo, impossível duplicação, tem-se uma situação de prestação exclusiva deste serviço por concessionário ou delegatário único, o que, mesmo em países com alto índice de competitividade na prestação de serviços públicos, constitui monopólio natural. A malha dutoviária, na prestação dos serviços de saneamento básico, é realizada de forma monopolística, por um único agente por região, sob pena de tornar o custo da atividade inviável. ${ }^{23}$

\footnotetext{
${ }^{21}$ As margens de rios e canais são sujeitas a riscos, sobretudo devido ao acúmulo de lixo nos canais, dificultando o escoamento de águas pluviais.[...] Com a negligência do poder público relativamente à limpeza e conservação de canais e galerias pluviais, ocorre que, na verdade, não apenas favelas, mas também bairros comuns são, de tempos em tempos, vitimados por enchentes. [...] Diferentemente de tais episódios catastróficos, que são esporádicos, a carência de saneamento básico é um constante fator de problema, sob a forma de doenças diversas. SOUZA, Marcelo Lopes. O desafio metropolitano: um estudo sobre a problemática sócio-espacial nas metrópoles brasileiras. Rio de Janeiro: Bertrand Brasil, 2000, p. 122.

${ }^{22}$ Para Alaôr Caffé Alves, nem todos os serviços de saneamento básico estão considerados no projeto de lei 266/96 que dispõe sobre as diretrizes para a concessão e permissão dos serviços públicos de saneamento da regulação e controle de sua prestação, tal como a não menção ao controle de vazões, acrescentando que este fato poderá acarretar problemas de regulação, controle e operação dos demais serviços de saneamento, visto que estão interligados em razão da gestão dos recursos hídricos e controles das bacias e sub-bacias hidrográficas. ALVES, Alaôr Caffé. Saneamento básico: concessões, permissões e convênios públicos, Op. Cit., p. 115.
}

${ }^{23}$ SCHIRATO, Victor Rhein. Setor de saneamento básico: aspectos jurídico-administrativos e competências regulatórias. Revista de Direito Administrativo, Rio de Janeiro, n. 237, p. 120-121, jul-set/2004. 


\section{O Saneamento é a Base de toda Infraestrutura Urbana}

Problemas relacionados ao saneamento básico, especificamente na poluição de rios e no tratamento de esgotos, são conseqüências diretas da má ocupação urbana. Os loteamentos irregulares, e a ausência de uma infra-estrutura em bairros surgidos sem qualquer planejamento urbano, concentram situações incômodas ao ambiente urbano.

O Ministério das Cidades ${ }^{24}$, órgão da Administração Pública Federal responsável por políticas públicas referentes à habitação, saneamento e transporte urbano, tem disseminado a importância de programas e ações infra-estruturais que devem ser efetuadas antes de qualquer intervenção urbana em matéria de saneamento ambiental

A resposta é simples. Qualquer programa eficiente de intervenção (obras) urbana deve levar em conta a infra-estrutura já existente no local. Realizar uma ampla obra de drenagem urbana (dentre as forma de prestação do serviço de saneamento ambiental) em localidades em que o Poder Público municipal sequer realizará uma pavimentação trará benefícios de curtíssimo prazo. Obras de drenagem ou de expansão de rede de águas pluviais em bairros limítrofes ao Rio ou Niterói, como Nova Iguaçu ou São Gonçalo, por exemplo, sem que existam ou se projetem, concomitamente, ruas ou vias pavimentadas, em pouco tempo levará ao entupimento desta rede, tornando as instalações públicas existentes menos eficazes. Se o Poder Público local não teve condições técnicas e econômicas de pavimentar, dificilmente terá condições de manter todo sistema de drenagem construído. Trata-se de princípio de economicidade das ações administrativas.

Daí porque a base de toda política de intervenção urbana devem ser as ações de saneamento ambiental. Ruas sem galerias levam ao despejo de águas no asfalto, diminuindo sua duração. Sem esgotos tratados, os rios perdem oxigenação, comprometendo o abastecimento de água a médio ou longo prazo.
TOSHIO MUKAI, abordando relatório técnico da Organização Mundial de Saúde (Boletim n. 297, série relatórios técnicos, 1.965), reproduz que as normas e planejamento físico mais válidas são as que se apoiam em normas sanitárias e que consideram, portanto, os problemas de saneamento. ${ }^{25}$

Entendemos plenamente aplicável esta orientação exercida pela Administração Federal, como uma medida indutora e regulatória, amparada pelo art. 21, XX, Constituição da República, podendo ser esta uma das diretrizes a ser seguida pela União, para a implantação de políticas de desenvolvimento urbano.

\section{As Etapas do Processo de Saneamento, Integra- das no Abastecimento Urbano de Águas e Esgotos}

Neste tópico abordaremos as ações e temas conexos com o saneamento ambiental. O saneamento ambiental possui vários enfoques que buscam a preservação do espaço urbano, protegendo-o contra agressões ambientais e urbanas.

A seguir são elencados os sistemas conexos com o abastecimento de águas. Todas estas etapas são consideradas essenciais pela Agenda 21, da qual participa o Brasil.

\subsection{Abastecimento de água e tratamento e lança- mento de esgotos}

Adotando como modelo de gestão institucional as operações da $\mathrm{SABESP}^{26}$ podemos identificar os arranjos urbanos de gestão das águas urbanas, divididos em quatro partes, que configuram subsistemas:

a)Produção de água ${ }^{27}$ potável: envolvendo algumas ou todas as suas unidades : reservatórios de regularização, obras de captação, estações de bombeamento, adutoras de água bruta, estações de tratamento e adutoras de água potável;

${ }^{24}$ República Federativa do Brasil. Programa de drenagem urbana. Manual para apresentação de propostas - 2005. Brasília: Ministério das Cidades, 2005.

${ }^{25}$ MUKAI. Toshio. Direito ambiental sistematizado. 5. ed. - Rio de Janeiro: Forense Universitária, 2005. P. 126

${ }^{26}$ CAFÉ ALVES, Alaor. Saneamento básico: pareceres, concessões, permissões. Bauru: Edipro, 1998.

${ }^{27}$ A água é recolhida num manancial e aduzida em tubulações até a estação de tratamento. MOTA, Roberto.Trópico e saneamento, Op. Cit., p. 50. 
b)Distribuição de água potável, envolvendo algumas ou todas as suas unidades: reservatórios de distribuição, subadutoras, estações de bombeamento, redes de distribuição e ramais prediais;

c)Coletas de esgotos urbanos, envolvendo algumas ou todas as suas etapas: ramais prediais, redes coletoras, estações elevatórias e coletores-troncos;

d)Afastamento de esgotos urbanos, envolvendo algumas ou todas as suas etapas: interceptores, emissários, estações elevatórias, estações de tratamento e obras de disposição final;

Esclareça-se que algumas destas etapas ou unidades pode constituir um serviço, administrado por uma instituição específica, formalmente independente das demais, exceto pelo fato de que as instalações devem ser todas integradas sob os pontos de vista físico e funcional.

Outros serviços auxiliares encontram-se igualmente inseridos no contexto ambiental urbano, os quais são objetos de debate junto à Agenda 21. O manejo das águias pluviais, decorrentes de águas residuais, incluindo aqui as chuvas (associada a técnicas de reuso de águas residenciais e industriais), em conjunto com a gestão dos resíduos sólidos, devem ser encaradas como um conjunto importante de ações interligadas por parte do poder público.

\subsection{Resíduos sólidos}

Dentre os principais poluentes do solo e do subsolo estão os resíduos sólidos, sendo assim considerados qualquer lixo, refugo, lodo, lamas e borras resultantes de atividades humanas de origens domésticas, profissionais, agrícolas, industriais, nucleares ou de serviço que neles se depositam.

A legislação aplicável, conforme art. $3^{\mathrm{a}}$ da Lei 6.938/81, define como lixo as substâncias sólidas, líquidas ou gasosas ou em qualquer estado de matéria que são capazes de gerar poluição. A quantidade de lixos produzidos se agrava na medida em que se detecta um crescimento demográfico desordenado, nitidamente nas áreas metropolitanas.

Considera-se o lixo como tendo natureza jurídica de direito difuso, assim como os bens ambientais. O extermínio dos lixões, com a adequação de seus problemas é uma questão relacionada com políticas públicas de saneamento ambiental. O direito ao meio ambiente equilibrado impõe ao estado o dever de agir. Várias são suas classificações: hospitalares, radioativos e nucleares, químicos, e o lixo urbano comum, resíduos de uso doméstico e da manutenção e limpeza pública, nas cidades.

Qualquer destinação do tratamento de resíduos deve ser precedida de estudo de impacto ambiental e respectivo relatório, sendo uma destas técnicas a deposição, a aterragem, a compostagem, o reaproveitamento energético de aterros. ${ }^{28}$

Estudo realizado na Região Metropolitana de São Paulo constatou 2.300 áreas contaminadas por resíduos industriais, a existência de 116 lixões, onde são depositados resíduos domésticos e industriais sem nenhum controle. Os depósitos de lixo a céu aberto provocam sérias implicações à saúde pública. $\mathrm{Na} \mathrm{Ba-}$ cia do Rio Paraíba do Sul, os resíduos não tratados e despejados em rede fluvial provocam o aumento dos custos do tratamento desta água que abastece mais da metade da população carioca e fluminense, ${ }^{29}$ além da parcela paulista e mineira que utilizam o manancial.

\subsection{Manejo da águas pluviais}

O manejo de águas provenientes de chuvas tem dois aspectos importantes para a proteção das águas: garantir um reaproveitamento com baixo custo de tratamento, ou mesmo sua utilização para usos não consuntivos; garantir que os rios recebam estas águas, possibilitando uma melhor racionalização de seu uso.

\footnotetext{
${ }^{28}$ Aterro sanitário - técnica de disposição do lixo, fundamentado em critérios de engenharia e normas operacionais específicas, que permite a confinação segura, em termos de controle da poluição ambiental, e proteção à saúde pública. Aterro controlado - local utilizado para despejo do lixo coletado, em bruto, com cuidado de, após a jornada de trabalho, cobri-lo com uma camada de terra, sem causar danos ou riscos à saúde pública e a segurança, minimizando os impactos ambientais.

Lixão ou Vazadouro a céu aberto - disposição final do lixo pelo seu lançamento, em bruto, sobre o terreno sem qualquer cuidado ou técnica especial . Vazadouro em áreas alagadas - disposição final do lixo pelo seu lançamento, em bruto. Disponível em: http://www.ibge.gov. br/home/presidencia /noticias/27032002pnsb.shtm. Acesso em 15/ jan / 2006.

${ }^{29}$ FIORILLO, Celso Antonio Pacheco; RODRIGUES, Marcelo Abelha. Manual de direito ambiental e legislação aplicável. São Paulo: Max Limonad, 1999, p. 428.
} 
A expansão urbana provoca a impermeabilização do solo, ${ }^{30}$ entre outros impactos. Assim, a parcela de água que anteriormente se infiltrava no solo passa a escoar pelos condutos, aumentando o escoamento dinâmico, tendo o rio como receptor final, geralmente. Em muitos casos, em cidades e metrópoles, as redes de águas pluviais concentram os serviços de rede de esgotos, provocando uma concentração de águas em rede de esgotos, quando não há galerias específicas para este fim, neste último caso, exigindo maior dimensionamento das redes, o que usualmente não ocorre. A ausência de compromisso e comportamento ambiental da população também favorece o lançamento de resíduos alimentares e objetos nestas galerias, que não estão preparadas para estas finalidades.

\section{As Competênias Constitucionais em Matéria de Saneamento}

Não há um único responsável pela gestão dos serviços de saneamento conforme interpretação constitucional de alguns dispositivos que, a seguir, discutir-se-ão.

No art. 21, XXI, vislumbramos a atribuição da União para estabelecer diretrizes gerais em matéria de saneamento, envolvendo outros aspectos como habitação e transportes urbanos.

Identificamos, no art. 23 da Constituição da República, a competência comum das três esferas administrativas governamentais, de atuarem na preservação do verde, do meio ambiente e da saúde.

As competências constitucionais concorrentes, elencadas no art. 24 da Constituição Federal, dentre as várias espécies de competências legislativas reproduzidas, são as que melhor mostram relação com a matéria de saneamento, pois, ainda que não disponham expressamente sobre o tema, incidentalmente oferecem mecanismos de uma normatização parcial sobre o tema, envolvendo preservação do meio ambiente e urbanismo.
Importante se torna identificarmos que há uma distinção entre competências administrativa e legislativa separadas didaticamente pelos constituintes nos arts. 21 e 22, bem como as competências legislativas federais, estaduais e locais distribuídas ao longo do arts. 22, 24, 30, sem considerar as competências expressas dos estados-membros em algumas matérias difusamente dispostas na Constituição Federal, tais como educação, segurança pública (art. 34) e distribuição de gás canalizado.

\subsection{As diretrizes gerais em matéria de saneamento}

A competência, em matéria legislativa da União, é traçada nos arts. 22 e 24 . No primeiro conjunto, temos as competências exclusivas que, em determinados incisos, como, por exemplo, o inciso XXVII, garantem à União atribuição para editar normas gerais. Esta sistemática não é aludida no art. 21, inciso XX, que se refere a diretrizes a serem traçadas pela União, em matéria de saneamento básico.

As normas de caráter geral, abrangentes sob os aspectos nacionais, são veiculadas nas competências concorrentes, que abrangem as matérias referentes a direito urbanístico, meio ambiente (inciso VI), defesa da saúde. As diretrizes envolvem algo mais amplo. A diretriz é uma norma de conduta a ser seguida para garantia dos fins e objetivos determinados por uma política pública ou programas. Consiste em estabelecer critério para adoção de políticas públicas.

A atribuição para estabelecer diretrizes gerais coloca a União como a gestora, em nível nacional, de um sistema de saneamento, uma vez que todos os entes podem atuar nesta área, sendo os de atuação local aqueles que dispõem de sua titularidade. A política pública $^{31}$ é a opção por um modelo a ser institucionalizado.

As diretrizes gerais para os serviços de saneamento e de uma política nacional de recursos hídricos, dando efetividade ao art. 21, XIX e XX, significam o exercício do poder federal, cujo impulso é reservado à União, sendo estas classificadas como atribuições de

${ }^{30}$ MUSETTI, Rodrigo Andreotti. A canalização de córregos e o direito à paisagem hídrica. Revista de Direitos Difusos, São Paulo, v. 16, p. 2159 , nov./dez. 2002 .

${ }^{31}$ Políticas públicas são programas de ação governamental visando coordenar os meios à disposição do Estado e as atividades privadas, para realização de objetivos socialmente relevantes e politicamente determinados. CARVALHO, Cláudio Oliveira. Políticas públicas e gestão urbana-ambiental. Revista de Direito Ambiental, São Paulo: Revista dos Tribunais, n. 26 , p. 278, abr./jun. 2002. 
caráter de desenvolvimento, ${ }^{32}$ normatizando políticas nacionais. Esse espectro de diretrizes, é bastante amplo de regulamentos em matéria de recursos hídricos e meio ambiente, faltando um sistema atualizado sobre uma política nacional de saneamento básico, a partir dos diversos debates sobre competência local e regional.

10.2. A possibilidade de estados e municípios legislarem suplementarmente e atuarem em questões urbano-ambientais

A definição de diretrizes a partir de normas federais leva à conclusão de que os entes menores poderão dispor de medidas legais peculiares sobre o tema. Tomando, como exemplo, a gestão das bacias hidrográficas, art. 21, inciso XIX, o inciso irmão do dispositivo referente às diretrizes de saneamento, art. 21, inciso XX, verificamos a possibilidade da atuação compartilhada dos entes federativos, na normatização da questão de águas urbanas. Neste último caso, ainda que a titularidade das águas esteja situada nas esferas federal e estadual, aos municípios cabe zelar pelo cumprimento de lei federal, em especial em questões de saneamento e meio ambiente.

Alinhada a esta colocação, em se tratando de gestão urbana, possuem os estados-membros competência para legislar sobre direito urbanístico, art. 24, inciso I da Constituição Federal, principalmente em se tratando de questões de caráter regional metropolitano, quando assumem competência exclusiva para definir tais serviços como de interesse comum, art. 25 $\S 3^{\circ}$ da Constituição Federal. Aos municípios compete a atribuição concernente ao parcelamento do solo urbano, conforme art. 182 da Constituição Federal, incluindo, num leque mais amplo de normas urbanísticas, a Lei Orgânica Municipal e, também, os planos diretores municipais.

Em matéria de saneamento básico, a competência legislativa suplementar está vinculada à possibilidade de legislar sobre serviços de interesse comum, nos termos do art. $25, \S 3^{\circ}$. Em matéria de recursos hídricos, da mesma forma, a competência suplementar decorre de necessidade de autonomia regulatória para estabelecer diretrizes suplementares para utilização do bem estadual.

A competência municipal, em matéria de meio ambiente, é prevista constitucionalmente no art. 23, incisos II, IV, VI e VII, a ser exercida em conjunto com a União e estados-membros. ${ }^{33}$ São as competências no âmbito executivo, de caráter comum, que apontam a sua competência suplementar de promoção do adequado ordenamento territorial e controle do uso do solo urbano, art. 30, inciso VIII, reconhecida pela intervenção local, na esfera estética, de posturas e urbana, questões vinculadas aos aspectos ambientais.

\section{Fatores que Interferem na Prestação dos Servi- ços de Saneamento}

\subsection{Os aspectos geográficos, como parâmetros de titularidade do serviço de saneamento}

Tomando o aspecto geográfico como fator preponderante para atuação do Estado, na questão de águas urbanas, temos alguns aspectos importantes, especificamente um ponto que pode ser levantado, para retirar da esfera meramente municipal a atribuição de quaisquer serviços referentes à gestão urbana de águas: a possibilidade de escassez do bem, problema que pode comprometer o princípio da dignidade humana, fundamento do nosso modelo republicano federativo. Há necessidade intrínseca de preservação do bem, de gestão econômica dos recursos hídricos, mesmo em sede local.

\subsection{A titularidade do bem como fator determinan- te}

O constituinte originário rompeu com a visão privatista e municipalista da titularidade do bem "água”.

A Constituição do Brasil reconhece, nos arts. 20 e 26, o domínio sobre as águas em favor das entidades União e Estados-membros, sendo o critério utilizado o da exclusão mútua.

Algumas atribuições delegadas aos entes federativos, entretanto, estão diretamente associadas à disponibilidade e titularidade de determinado bem, ou

\footnotetext{
${ }^{32}$ Cf. HORTA, Raul Machado. Direito constitucional. 3. ed. Belo Horizonte: Del Rey, 2002, p. 349.

${ }^{33}$ SILVA, José Afonso. Direito ambiental constitucional. 5. ed. São Paulo: Malheiros, 2004, p. 79.
} 
instalações, à entidade delegatária ou concedente.

Em se tratando de serviços de telecomunicações, a competência administrativa para prestação do serviço, nos termos do art. 21, XI, está vinculado à titularidade, pela União, das vias de comunicações necessárias à prestação deste bem. Da mesma forma, as instalações hidrelétricas e, num sistema de completa ilação entre os mecanismos de gestão, os rios com potencial hidráulico, ambos no art. 20, III e VIII.

Os rios, como fonte de fornecimento de águas às cidades e núcleos urbanos, têm uma vinculação imediata e especial com o ente que lhes controla. Mecanismos de controle e exercício desta titularidade existem, podendo ser mencionados a outorga e a cobrança pelo uso, já mencionadas como instrumento de precaução ${ }^{34}$.

Luís Roberto Barroso salienta que a determinação do titular do domínio da água é fundamental para o estudo do saneamento básico, pois quem quer que seja o ente competente para prestar o serviço, em cada caso deverá obter uma outorga do proprietário da água, a não ser, evidentemente, que seja o proprietário. ${ }^{35}$

Mesmo com toda divisão que possa existir, e essa divisão ocorre entre os doutrinadores, ou mesmo a ausência de uma visão macro-ambiental deste problema, existem serviços públicos definidos em lei que dependem do exercício da titularidade para possuírem efetividade e eficácia.

Vejamos o caso estampado na Lei 9.074/95, em seu art. $1^{\circ}$, inciso $\mathrm{V}$, que regulamenta as concessões para os serviços de drenagem, irrigação, barragem. Esta lei proporciona uma complementação, um auxílio à definição dos serviços de irrigação. Considerando que estes serviços de irrigação somente podem ser realizados em função de captação de fonte hídrica superficial ou subterrânea, podemos entender que a discussão da titularidade da fonte está estritamente relacionada à delegação do serviço. Em se tratando de utilização pelo particular, em função da captação direta de água para utilização em fins agrícolas, não há como separar poder-concedente de poder-titular do bem. Diferente é no sistema de saneamento, quando há uma prestação efetiva de derivação hídrica (potabilidade, distribuição, coleta), e, não, a mera captação do bem como nos serviços de irrigação.

Jerson Kelman, primeiro presidente da Agência Nacional de Águas, entidade implementadora do Sistema Nacional de Gerenciamento de Recursos Hídricos, delineia a situação desta autarquia reguladora no contexto das ações que envolvam a participação desta entidade, no qual, à ANA, não interessa como é que o Estado está alocando e gerenciando seus recursos hídricos dentro do Estado, desde que haja uma entrega da água no rio principal de domínio da União que tenha sido pactuada. Então, cabe à União monitorar essas condições pactuadas e, se não forem cumpridas, fiscalizar, supletivamente, os demais rios da bacia hidrográfica, quando houver violação do pacto. ${ }^{36}$

Fica bastante evidente que o papel de um sistema de gerenciamento de águas não se restringe a fiscalizar o uso isolado de uma determinada fonte, mas ao sistema integrado, ainda que não exista única titularidade.

\subsection{Aspecto geopolítico como determinante}

As regiões de ação administrativa conjunta são inauguradas com a criação das regiões de desenvolvimento integrado. O principal motivo da existência desta atuação integrada, sujeita à orientação de entidade federativa, era a atenuação das más condições de vida das populações localizadas em regiões carentes de todos e quaisquer serviços. Posteriormente, com o fenômeno da ocupação desordenada e incontrolada dos espaços urbanos industriais, temos o desenvolvimento das metrópoles. Sobre dois prismas, ambos de incidência geopolíticos, temos os arts. 25 e 43, da Carta Magna. ${ }^{37}$

\footnotetext{
${ }^{34}$ JUSTEN FILHO, Marçal. Parecer elaborado pelo professor doutor Marçal Justen filho, versando sobre a minuta de anteprojeto da lei da política nacional de saneamento básico. Disponível em www.cidades.gov.br. Acesso em 10/ago /2005.

${ }^{35}$ BARROSO, Luís Roberto. Saneamento básico: competências constitucionais da união, estados e municípios. Revista de Informações Legislativas, Brasília, v 153, ano 38, p. 257, jan./mar. 2002.

${ }^{36}$ KELMAN, Jerson. Comentários aos anteprojetos de lei. In Seminário "Água, desafio para o próximo milênio", Ministério do Meio Ambiente-SRH, p. 46.

${ }^{37}$ A Constituição concede aos estados, no art. $25 \S 3^{\circ}$, o direito de instituir regiões metropolitanas, aglomerações urbanas e microrregiões para fins de planejamento e execução de outras ações. Descentraliza-se a autoridade para legislar sobre o recorte espacial do planejamento, embora sua dimensão macro permaneça nas mãos da União, como reza o art. 43. LAVINAS, Lenha; MAGINA, Manoel A. O Brasil e as desigualdades regionais: os debates na revisão constitucional. Aquecimento global. Revista Ciência Hoje, v. 18, n. 107, p. 35, 1995.
} 
Percebemos que não há definição precisa de quais às ações a serem empreendidas pelo Poder Público nestas áreas. Existe a previsão de, expressamente nas áreas de desenvolvimento integrado, haver ação federal para a utilização, o manejo de recursos hídricos, entre outras funções de interesse regional a serem empreendidas, conforme dispõem os art. 21, XVIII, e art $43, \S 2^{\circ}, I V$. Assim, podemos entender que as questões relacionadas ao fornecimento de água, essencial à sobrevivência humana e prevenção de doenças, é matéria de interesse de todas as esferas governamentais.

Esta atuação com base no princípio do regionalismo, é de competência da União, conforme art. 21, IX, sob a forma de planejamento integrado nacional e territorialmente. O planejamento de ações públicas integradas, da mesma forma, é previsto no art. 25 que trata das regiões metropolitanas. A ação planejada levou o Poder Federal a estruturar vários órgãos e entidades para agirem, especificamente, nestas regiões carentes. É de conhecimento público que a Região Nordeste tem problemas históricos relacionados com o fornecimento de água, razão pela qual existem vários organismos federais que atuam nestas áreas, tais como DNOCS, CODEVASF, SUDENE, ${ }^{38}$ cujas funções são desenvolver programas de combate à desigualdade regional.

Marcos Juruena descreve que os setores de distribuição obedecem à lógica de bacia hidrográfica e, não. à divisão político-administrativa do município. ${ }^{39}$ Logo, a síntese é que os limites geopolíticos municipais não oferecerão soluções para as situações envolvendo abastecimento de água.

\subsection{A distribuição de competências referente à ti- tularidade entre as diversas esferas}

A sistemática constitucional para os serviços públicos de saneamento provoca a incerteza sobre a titularidade dos serviços de saneamento básico, que não é delineada a qualquer ente federativo.

O critério padronizado tem sido o do exercício de atribuição local (estadual ou municipal), com base na gestão exclusiva das etapas dos serviços por parte de um único município, sem qualquer repercussão nos municípios vizinhos. Entende-se que todas as etapas do processo de saneamento devem ser operadas na territorialidade do município. Ou seja, qualquer comprometimento na gestão de um município X, em nada atingirá o fornecimento de águas no município Y vizinho, salvo em longo prazo, em função do comprometimento da disponibilidade do bem. Este não é o nosso objeto de estudo.

Sob este raciocínio, não há como excluir a atuação de ente com atribuições de espectro regional, os estados-federados, em se tratando de questões metropolitanas, nos termos do conhecido art. $25 \S 3^{\circ}$, Constituição Federal.

Da mesma forma, não podemos excluir a possibilidade, e bastante concreta, de atuação do ente federal nos aspectos geoeconômicos regionais, nitidamente em áreas de baixa qualidade de vida, de baixa renda, sem acesso às condições indispensáveis de vida, que via de regra demandam ações mais drásticas por parte do poder público, conforme o art. 43 da Constituição. Como não há qualquer relação entre titularidade do bem e gestão e titularidade dos serviços de fornecimento de águas urbanas, em se tratando localidades rurais mais afastadas que são, na realidade, núcleos de moradores de periferia, podemos ter uma atuação do Ente Federativo Maior, com o devido embargo quanto à proteção ou preservação das águas subterrâneas, de titularidade estadual. Neste particular, Cid Tomanik Pompeu ${ }^{40}$ critica a titularidade exclusiva dos estados-membros sobre os aqüíferos, no caso de águas subterrâneas que estejam depositadas em mais de um estado. Em nossa opinião, estes aspectos, manifestados pelo autor, somente servem para reafirmar a possibilidade de atuação do ente federal nas questões inter-regionais nacionais.

\footnotetext{
${ }^{38}$ O Departamento Nacional de Obras Contra a Seca é autarquia federal; a Companhia de Desenvolvimento do Vale de São Francisco é empresa pública federal e a Superintendência de Desenvolvimento do Nordeste (atual ADENE) é autarquia federal, todas vinculadas ao Ministério da Integração Nacional.

${ }^{39}$ SOUTO, Marcos Juruena Villela. Direito administrativo das concessões. Rio de Janeiro: Lumen Juris, 2004 , p. 291.

${ }^{40}$ POMPEU, Cid Tomanik. Apud GRAF, Ana Cláudia Bento. A tutela dos estados sobre as águas. In: FREITAS, Vladimir Passos (Org.) Águas: aspectos jurídicos e ambientais. Curitiba: Juruá, p. 64.
} 
11.5 O desenvolvimento sustentável e o meio ambiente

O sistema de gerenciamento de rios, lagos e correntes engloba um sistema de gestão ambiental. O ciclo de saneamento se inicia com a captação de água e finaliza com o lançamento de águas residuais coletadas sob a forma de dejetos. Nestas duas pontas, mencionadas como partes dos serviços de saneamento, há uma interdependência muito forte com o sistema de gestão hídrica. Inicialmente, porque o controle da água captada é de responsabilidade do gestor do bem e do gestor do sistema como um todo, que edita regras técnicas a serem seguidas por todos os entes federativos. No outro extremo, na mesma condição de gestor do sistema nacional, ao órgão regulador da fonte e do sistema de gerenciamento cabe a responsabilidade de fiscalizar o lançamento de resíduos nas fontes hídricas. A definição sobre a competência para fiscalizar o lançamento está vinculada à titularidade da fonte, ao contrário de uma visão global e sistêmica, que envolveria um controle múltiplo para evitar a inoperância do ente titular, omisso administrativamente. A preservação do bem é uma questão de desenvolvimento sustentável e, não, de titularidade do bem. O domínio vincula uma relação econômica, não necessariamente normativa. Logo, não há política estadual de recursos hídricos pela simples dominialidade do bem, mas em função da competência de preservação ambiental que envolve toda relação.

O planejamento da bacia hidrográfica é uma realidade que independe da esfera administrativa e governamental. $\mathrm{O}$ equilíbrio das demandas e a disponibilidade de água são questões regulatórias de preservação de um bem difuso, integrante do meio ambiente. Assim, toda a fase que interfere, diretamente, na preservação do bem não é questão isolada de um sistema de saneamento, mas, no mínimo, interligada. No melhor cenário, os serviços de saneamento dependem da proteção das águas. Alguém poderia argüir, por que esta atuação de possível interferência num sistema de tratamento não poderia ser exercida sobre determinada indústria, assim como esta- mos apresentando ao setor de saneamento? A resposta está na característica do serviço. O saneamento, quando oferecido à coletividade, é serviço público e, não, uma atividade econômica. $\mathrm{O}$ tratamento de resíduos em instalações industriais decorre de uma seqüência de atividades operacionais de empresas, sujeitas às mesmas normas de meio ambiente que vinculam as entidades prestadoras de serviços de saneamento.

Podemos afirmar que estas fases do ciclo de saneamento, captação de água e lançamento de dejetos, localizadas nas suas extremidades, não estão afastadas de um sistema gerenciado de forma mais ampla, para garantir maior proteção e integração das ações ambientais.

\section{Conclusão}

As atribuições dos entes federativos nestas áreas não são descritas com a clareza necessária para excluir possíveis discordâncias entre as esferas governamentais, devendo haver uma ação cooperada, primando pela descentralização e pela participação da sociedade.

Não há como afastar a gestão dos rios das ações relativas a saneamento. São pontas da mesma linha condutora, na qual uma gestão turbulenta na área de saneamento provocará um desconcerto no meio ambiente, sendo este imprescindível à qualidade de vida e proteção da saúde pública.

Não há como imaginar que a prestação dos serviços de águas e esgotos seja destacada de outros temas que interferem na participação dos entes, dentro de uma responsabilidade federativa que se aproxima da atuação harmônica entre as esferas, no empreendimento de serviços sob uma nova ótica de meio ambiente urbano e regionalizado.

A questão hídrica possui interfaces que vão além dos aspectos locais. O planejamento das ações de intervenção urbana passa pelo debate em torno do papel dos comitês de bacias hidrográficas, órgãos de participação dos diversos setores que pretendem garantir a preservação do bem a gerações futuras.

\section{Informações bibliográficas:}

Conforme a NBR 6023:2002 da Associação Brasileira de Normas Técnicas (ABNT), este texto científico publicado em periódico eletrônico deve ser citado da seguinte forma:

SANTOS, B. S.. A Introdução ao Federalismo das Águas: interfaces entre gestão de bacias hidrográficas e saneamento básico. Cadernos UniFOA, Volta Redonda, ano II, n. 4, agosto. 2007. Disponível em: $<$ http://www.unifoa.edu.br/pesquisa/caderno/edicao/04/41.pdf $>$ 